\title{
Электрические свойства GaAs нитевидных нанокристаллов, выращенных на гибридных подложках графен/SiC
}

\author{
() П.А. Алексеев ${ }^{1}$, М.С. Дунаевский ${ }^{1}$, А.О. Михайлов ${ }^{1}$, С.П. Лебедев ${ }^{2}$, А.А. Лебедев ${ }^{1}$, \\ И.В. Илькив ${ }^{3}$, А.И. Хребтов ${ }^{2}$, А.Д. Буравлев ${ }^{1,3,4}$, Г.Э. Цырлин ${ }^{2,3,4}$ \\ ${ }^{1}$ Физико-технический институт им. А.Ф. Иоффре Российской академии наук, \\ 194021 Санкт-Петербург, Россия \\ ${ }^{2}$ Санкт-Петербургский национальный исследовательский университет \\ информационных технологий, механики и оптики, \\ 197101 Санкт-Петербург, Россия \\ ${ }^{3}$ Санкт-Петербургский национальный исследовательский Академический университет, \\ 194021 Санкт-Петербург, Россия \\ ${ }^{4}$ Институт аналитического приборостроения Российской академии наук, \\ 190103 Санкт-Петербург, Россия \\ E-mail: npoxep@gmail.com
}

(Получена 9 апреля 2018 г. Принята к печати 17 апреля 2018 г.)

Исследовались электрофизические свойства GaAs нитевидных нанокристаллов, выращенных на поверхности (0001) 6H-SiC-подложки, покрытой моно- и бислоями графена. Нитевидные нанокристаллы были выращены методом молекулярно-пучковой эпитаксии с использованием золота в качестве катализатора. Исследование электрофизических свойств производилось путем измерения и анализа вольт-амперных характеристик одиночных нитевидных нанокристаллов, вертикально растущих на подложке. Численное моделирование измеренных вольт-амперных характеристк выявило наличие шоттки-барьера высотой $\sim 0.6 \mathrm{~B}$ между нитевидными нанокристаллами и графеном. Возникновение барьера связано с формированием избыточного мышьяка на интерфейсе нитевидный нанокристалл/графен.

DOI: 10.21883/FTP.2018.12.46766.8882

\section{1. Введение}

Хорошо известно, что GaAs нитевидные нанокристаллы (ННК) являются перспективными материалами для создания приборов оптоэлектроники и фотоники нового поколения. Среди них в последнее время особое внимание уделяется разработке лазеров, фотодиодов и солнечных элементов на основе массивов вертикально стоящих ННК [1]. Очевидно, что при создании подобных приборов необходимо обеспечить достаточную прозрачность электрических контактов к массивам ННК. Поэтому в качестве верхних контактов часто используется ITO или AZO, сетка металлических, чаще всего серебряных, нанопроводов или графен [2-4]. Недавно была продемонстрирована возможность использования в качестве верхнего прозрачного контакта графена и мультиграфена. При этом было показано, что между графеном и ННК возникал шоттки-барьер [5,6]. В данном случае использовался перенесенный графен, предварительно выращенный на медных подложках. Однако проводимость подобных слоев графена уступает проводимости отшелушенного графена вследствие большого числа дефектов. В свою очередь получение отшелушенных слоев графена относительно большой площади представляет собой достаточно сложную задачу, что в значительной степени затрудняет создание приборов на его основе. Тем не менее существует еще один альтернативный способ изготовления высококачественного графена большой площади, основанный на термической деструкции $\mathrm{Si}$ грани $\mathrm{SiC}[7,8]$. При этом $\mathrm{SiC}$ как широкозонный материал является прозрачным в видимом и ИК диапазонах, что позволяет рассматривать его также в качестве основы приборных структур, а также защитного материала, способного выдержать опасные условия работы. Поэтому в последнее время стало уделяться пристальное внимание вопросам, связанным с синтезом ННК на подобных гибридных материалах, и исследованиям их свойств. Так, например, недавно была продемонстрирована принципиальная возможность выращивания массивов GaAs HHK на подложках мультиграфен (3-5 слоев)/SiC [9]. Также была продемонстрирована возможность выращивания на таких подложках $\mathrm{GaN}$ и InAs HНK [10,11]. Тем не менее, очевидно, что электрические свойства приборов на основе массивов вертикально стоящих ННК во многом будут определяться параметрами электрических контактов к ним. Несмотря на активные исследования особенностей роста НHК на графен/SiC-подложках, электрические свойства контакта между $\mathrm{HHK}$ и графен/SiC практически не изучены.

Цель данной работы - изучение возможности синтеза массивов $\mathrm{GaAs} \mathrm{HHK}$ на графен/SiC-подложке c помощью метода молекулярно-пучковой эпитаксии (МПЭ) и исследование электрических свойств контакта ННК-графен. 


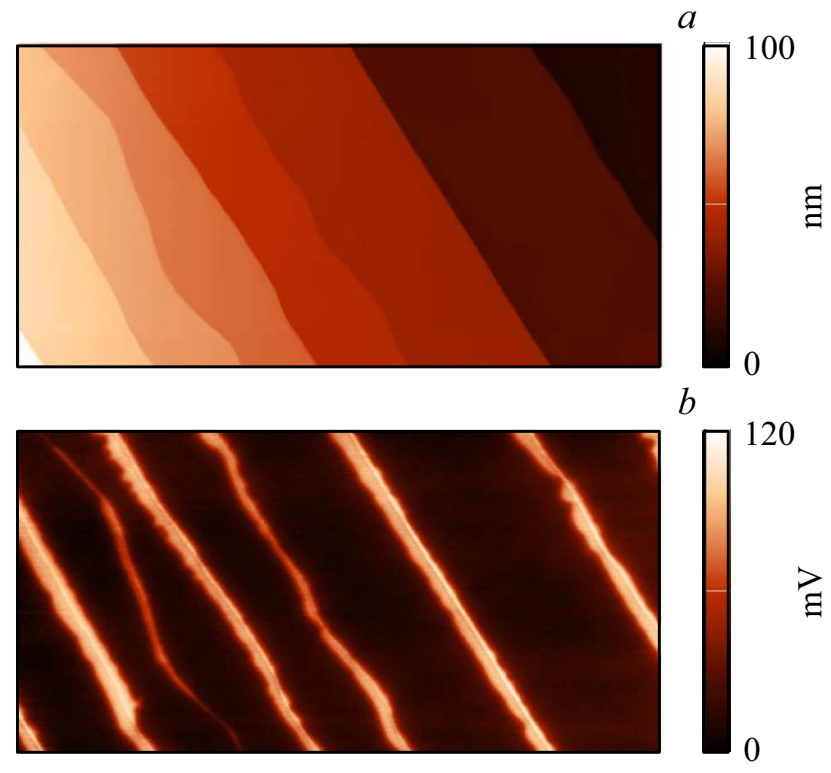

Рис. 1. Участок поверхности образца со слоями графена на подложке $\mathrm{SiC} 10 \times 5$ мкм. $a-$ изображение АCM топографии и слоев графена на поверхности $\mathrm{SiC} . b-$ карта распределения поверхностного потенциала. Светлые полосы соответствуют участкам с двухслойным графеном.

\section{2. Образцы и методика эксперимента}

\section{1. МПЭ синтез GaAs нитевидных нанокристаллов}

GaAs HНК выращивались на подложках $6 H$-SiC, поверхность (0001) которых была покрыта графеном. Получение графена на таких подложках производилось методом термодеструкции $\mathrm{Si}-г$ рани $[8]$.

На рис. 1, $a, b$ представлены АСМ (атомно-силовая микроскопия) изображение топографии поверхности $(a)$ и карта распределения поверхностного потенциала $(b)$ участка поверхности $\mathrm{SiC}$ со слоями графена. Поверхность образца имеет ступенчатую структуру с высотой ступенек 5-10 нм и шириной террас $\sim 1$ мкм. На карте распределения поверхностного потенциала рис. $1, b$ наблюдаются светлые вытянутые полосы, расположенные вдоль границы террас. Светлые полосы соответствуют участкам с двухслойным графеном, поверхностный потенциал которого, как правило, на 90-120 мВ выше однослойного графена [12]. Из рисунка следует, что более $90 \%$ площади подложки покрыто однослойным графеном (темные участки на рис. $1, b$ ).

Синтез GaAs HНК осуществлялся на установке молекулярно-пучковой эпитаксии Riber Compact 21TM, оснащенной дополнительной камерой для осаждения золота, которое использовалось в качестве катализатора для роста ННК, в условиях сверхвысокого вакуума. После предварительной очистки гибридных подложек они передавались в дополнительную камеру для создания массивов капель-катализаторов роста путем осаждения на разогретые до $500^{\circ} \mathrm{C}$ подложки атомов золота в течение 1 мин. Далее, после снижения температуры, образцы передавались в ростовую камеру, где и осуществлялся непосредственный синтез массивов GaAs HНК. Температура во время роста ННК, который продолжался 15 мин, поддерживалась одинаковой во всех экспериментах и составляла $500^{\circ} \mathrm{C}[13,14]$. Следует отметить, что были синтезированы как нелегированные, так и легированные бериллием массивы ННК, с уровнем легирования, соответствующим $5 \cdot 10^{18} \mathrm{~cm}^{-3}$ для объемных слоев.

\section{2. Измерение вольт-амперных характеристик одиночных нитевидных нанокристаллов}

Измерение вольт-амперных характеристик (BAX) одиночных GaAs HHК, выращенных на подложке со слоями графена, производилось с помощью сканирующего зондового микроскопа (С3M) Ntegra Aura (NT-MDT) при комнатных условиях. Схема эксперимента представлена на рис. 2. Для измерения ВАХ один электрод прижимался к поверхности графена, а вторым являлся СЗМ зонд с проводящим $\mathrm{W}_{2} \mathrm{C}$ покрытием. Использовались зонды FM_W $2 \mathrm{C}$ (NT-MDT). Перед измерением BAX предварительно производилось сканирование массива выращенных ННК в полуконтактном режиме. Для создания электрического контакта между СЗМ зондом и вершиной ННК зонд отводился от подложки на расстояние, равное длине ННК. Затем при подаче напряжения производилось перемещение зонда в латеральной плоскости. В точке, в которой регистрировалось наибольшее значение тока, осуществлялось измерение ВАХ. Измерения были произведены на десяти легированных и десяти нелегированных GaAs HНК.

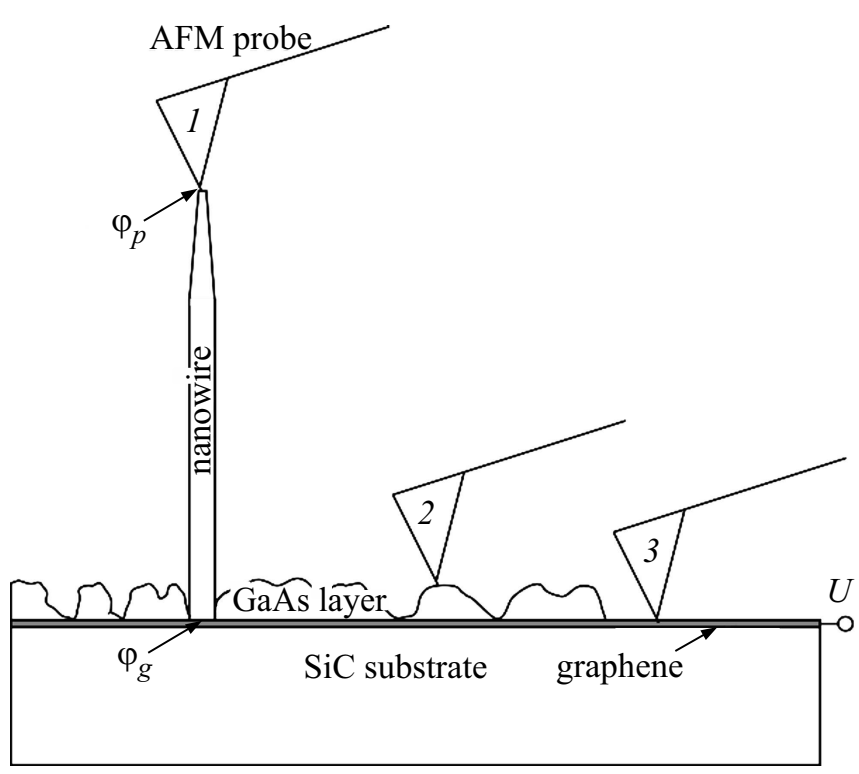

Рис. 2. Схема эксперимента по измерению ВАХ одиночных ННК с помощью СЗМ зонда. 


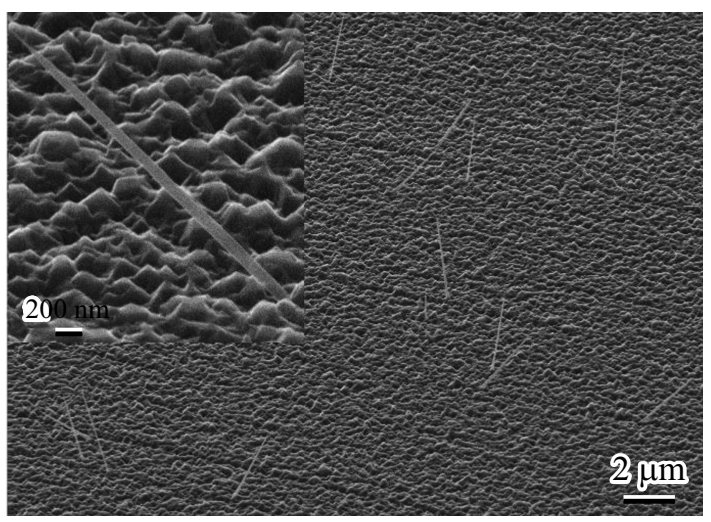

Pис. 3. РЭМ изображение массива GaAs HНК, выращенных на $\mathrm{SiC}$-подложке со сформированными слоями графена. На вставке приведено изображение одиночного GaAs HНК.

\section{3. Экспериментальные результаты и обсуждение}

На рис. 3 представлено характерное изображение массива легированных GaAs HНК, выращенных на графеновых слоях, полученное методом растровой электронной микроскопии (РЭМ). Видно, что диаметр синтезированных ННК составлял около 40-100 нм, а длина варьировалась в диапазоне 2-5 мкм. Наблюдалось сужение ННК к вершинам, при этом минимальный диаметр не превышал 10 нм. Следует отметить, что РЭМ изображения массивов легированных и нелегированных ННК не имели существенных отличий.

Из рис. 3 также следует, что при росте ННК на поверхности подложки происходило образование дополнительного смачивающего GaAs-слоя толщиной до 300 нм. При этом на топографии GaAs-слоя можно выделить полосы, направление которых совпадает с направлением террас на изначальной подложке.

Ранее было показано, что $\mathrm{A}^{\mathrm{III}} \mathrm{B}^{\mathrm{V}} \mathrm{HHK}$ на поверхности подложек $\mathrm{SiC}$ с слоями графена растут вдоль направлений, перпендикулярных поверхности [9-11]. Кроме того, в ряде работ наблюдался преимущественный рост ННК в областях с несколькими слоями графена по сравнению с монослойными участками $[15,16]$. При этом известно, что боковая грань ступеньки между террасами на $\mathrm{SiC}$ подложке покрыта бислоем графена и ориентирована не вертикально к плоскости подложки. Если синтез ННК осуществляется на этой грани, то могут формироваться наклонные ННК [16]. Из рис. 3 следует, что в нашем случае большинство ННК выросло под различными углами к плоскости подложки. Вертикально растущих ННК практически обнаружено не было. Следовательно, можно предположить, что ННК образовывались на участках с бислоями графена на границе террас, что и приводило к их наклонному росту.

На рис. 4, $a$ представлены ВАХ, измеренные на поверхности графена до (1) и после роста ННК (2).
При измерении ВАХ один контакт создавался зондом, второй являлся прижимным (положение 3 на рис. 2). До роста GaAs НHК сопротивление составило $\sim 1$ мОм и соответствует сопротивлению зонда. Стоит отметить, что $\mathrm{SiC}$-подложки были высокоомными, поэтому их проводимостью можно пренебречь. При измерении ВАХ после роста НHK GaAs-слой механически удалялся в двух местах. К одному из мест создавался неподвижный контакт, а во втором месте прижимался СЗМ зонд. Из рис. 4, $a$ следует, что GaAs-подслой снижает проводимость графена на 3 порядка. При этом контакты к графену после нанесения GaAs остаются омическими, и их сопротивление много меньше сопротивления GaAsслоя. Таким образом, при анализе BAX, измеренных на ННК, допустимо предположение, что ток протекает в цепи СЗМ зонд-ННК-графен-прижимной контакт.

На рис. $4, b$ приведены ВАХ, измеренные при контакте зонда с вершиной ННК (черная кривая - положение 1 на рис. 2) и GaAs-слоем (черные треугольники положение 2 на рис. 2), для легированного образца. Стоит отметить, что BAX, измеренные на нелегиро-
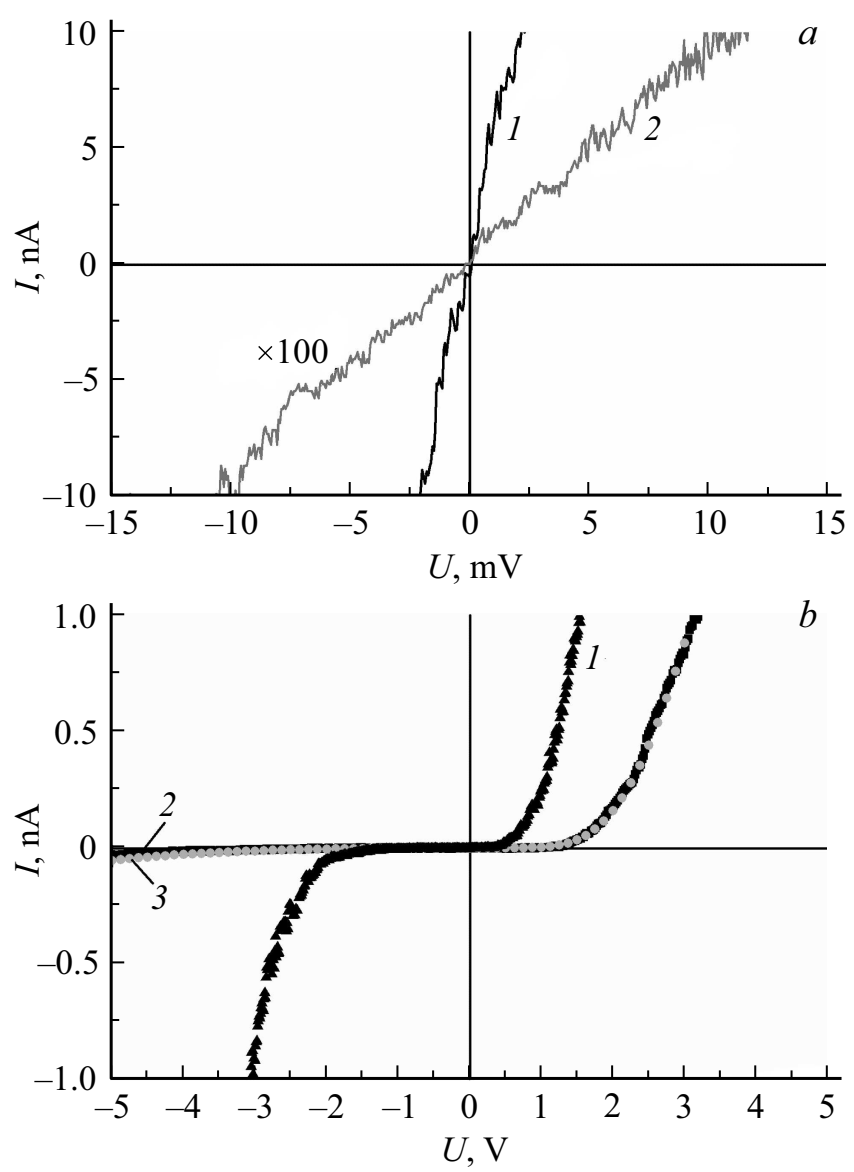

Рис. 4. $а$ - ВАХ слоев графена, измеренные до (1) и после (2) выращивания GaAs ННК. $b-\mathrm{BAX}$, измеренные при контакте зонда с GaAs-слоем (1) и вершиной ННК (2). Кривая 3 (серые точки) - ВАХ, полученная численным моделированием при высоте барьера между ННК и графеном $\varphi_{g}=0.62{ }_{\ni} \mathrm{B}$. 
ванных ННК в диапазоне напряжений \pm 10 В, выявили токи, сопоставимые по величине с чувствительностью используемого амперметра (30 пА). При этом наблюдался гистерезис ВАХ, что может свидетельствовать о значительном влиянии перезарядки естественного оксида на поверхности ННК на проводимость [17]. Кроме того, уровень фонового легирования в данном случае был неизвестен. Поэтому далее будут обсуждаться $\mathrm{BAX}$, измеренные только на легированных ННК. ВАХ, полученная на GaAs-слое, имеет пробойное напряжение $-2--3 \mathrm{~B}$, что соответствует уровню легирования $p^{+}=(1-5) \cdot 10^{18} \mathrm{~cm}^{-3}[18]$ и согласуется, как уже было отмечено выше (см. разд. 2.1), с возможными уровнями легирования ННК.

Форма BAX, измеренной на GaAs ННК, имеет асимметричный вид (см. рис. 4,b). При этом в прямом направлении (положительные напряжения) напряжение отсечки составило $\sim 1.5 \mathrm{~B}$. Известно, что для слабо легированных GaAs HНК, имеющих омический контакт с высоколегированной GaAs-подложкой и барьерный контакт между зондом и вершиной ННК, напряжение отсечки не превышает 1 В [19]. Следовательно, при росте GaAs ННК на графене, вероятнее всего, происходило формирование шоттки-барьера ( $\varphi_{g}$ см. рис. 1$)$. Таким образом, при измерении ВАХ ток протекал через два встречных шоттки-барьера: один $\left(\varphi_{p}\right)$ между зондом и ННК, а второй $\left(\varphi_{g}\right)$ между ННК и графеном.

Для анализа BAX, измеренной на одиночном GaAs ННК (черные квадраты на рис. 4, $b$ ), использовалось численное моделирование в программном пакете Silvaco TCAD. Стоит отметить, что использование аналитических методов при расчете ВАХ ННК может быть осложнено необходимостью учета сложной геометрии электрических контактов к ННК, а также вклада высокой плотности поверхностных состояний, термополевой эмиссии, эффектов экранировки и снижения высоты шоттки-барьера. При этом численное моделирование позволяет учитывать все вышеприведенные эффекты. Детальное описание механизмов, учитываемых при моделировании, представлено в [17]. В модель была заложена реальная форма ННК (диаметр 80 нм, длина 4 мкм). Диаметр верхнего контакта составлял $10 \mathrm{Hм}$, с соответствующей высотой шоттки-барьера $\varphi_{p}=0.55 \mathrm{~B}$. Плотность поверхностных состояний составляла $D_{\mathrm{it}}=3 \cdot 10^{12} \mathrm{~cm}^{-2}$. Диаметр нижнего контакта равнялся диаметру ННК. При моделировании производилось варьирование высоты шоттки-барьера между графеном и ННК, а также уровень легирования ННК в диапазоне $p^{+}=(1-5) \cdot 10^{18} \mathrm{~cm}^{-3}$. Полученные $\mathrm{BAX}$ сравнивались с экспериментальной. Наилучшее совпадение было получено при уровне легирования ННК $p^{+}=2 \cdot 10^{18} \mathrm{~cm}^{-3}$ и высоте шоттки-барьера $\varphi_{g}=0.62 \mathrm{~B}$ (серые точки на рис. $4, b$ ).

Высота барьера между ННК и графеном (0.62 В) близка по величине с высотой между ННК и СЗМ зондом $(0.55$ В). При этом данная величина согласуется с полученной ранее высотой шоттки-барьера между GaAs
ННК и графеном, перенесенным на поверхность массива GaAs HНК [5]. Недавно нами было показано, что закрепление уровня Ферми на поверхности $\mathrm{A}^{\mathrm{III}}$-As HНК имеет одинаковую природу, обусловленную образованием избыточного мышьяка на интерфейсе между ННК и естественным оксидом или металлом электрода [20]. Высота шоттки-барьера между графеном и ННК, схожая с высотой барьера к другим металлическим покрытиям, по-видимому, может указывать на формирование избыточного мышьяка на интерфейсе между ННК и графеном при эпитаксиальном росте. Известно, что при ван-дерваальсовой эпитаксии ковалентных связей между слоем графена и полупроводником не образуется. Безусловно, вопрос о полярности структуры нижнего слоя ННК не имеет определенного ответа, но вполне возможно, что при синтезе GaAs HНК начальная стадия роста была обусловлена наличием избыточного мышьяка на интерфейсе между ННК и графеном.

\section{4. Заключение}

Таким образом, в работе были синтезированы GaAs ННК на поверхности (0001) 6H-SiC-подложки, покрытой моно- и бислоями графена. Рост ННК осуществлялся преимущественно в областях с бислоями графена на границе ступеней, которыми была терминирована поверхность подложки. В процессе роста сформировался разупорядоченный массив ННК с произвольными углами наклона к плоскости подложки. Измерение ВАХ одиночных ННК с помощью СЗМ зонда выявило наличие шоттки-барьера между ННК и графеном. С помощью численного моделирования ВАХ была определена высота барьера, которая составила $\sim 0.6$ В. Полученная высота барьера согласуется с высотой шоттки-барьера в структурах, сформированных путем нанесения проводящих покрытий на поверхность GaAs. В данных структурах при нанесении покрытий происходило формирование избыточного мышьяка на интерфейсе, приводящее к закреплению уровня Ферми. Таким образом, при эпитаксиальном росте GaAs HНК на поверхности $\mathrm{SiC}$-подложки, покрытой слоями графена, по-видимому, также происходило образование избыточного мышьяка на интерфейсе, приводящее к формированию шотткибарьера высотой $\sim 0.6 \mathrm{~B}$. Обнаруженное явление затрудняет использование графена в качестве прозрачного омического контакта к массивам GaAs HНК, вместе с тем формирование шоттки-барьера позволяет использовать данные структуры в качестве солнечных элементов.

Работа поддержана грантом РФФИ № 16-32-60147 мол_а_дк. Синтез образцов был выполнен при финансовой поддержке Министерства образования и науки Российской Федерации (в рамках выполнения госзадания № 16.2483.2017/4.6 и $16.9789 .2017 /$ БЧ.) 


\section{Список литературы}

[1] P. Krogstrup, H.I. Jørgensen, M. Heiss, O. Demichel, J.V. Holm, M. Aagesen, J. Nygard, A.F. i Morral. Nature Photonics, 7, 306 (2013).

[2] L. Tsakalakos, J. Balch, J. Fronheiser, B. Korevaar, O. Sulima, J. Rand. Appl. Phys. Lett., 91, 233117 (2007).

[3] H. Zhang, X. Dai, N. Guan, A. Messanvi, V. Neplokh, V. Piazza, M. Vallo, C. Bougerol, F.H. Julien, A. Babichev, N. Cavassilas. ACS Appl. Mater. Interfaces, 8, 26198 (2016).

[4] A. Babichev, H. Zhang, P. Lavenus, F. Julien, A.Y. Egorov, Y. Lin, L. Tu, M. Tchernycheva. Appl. Phys. Lett., 103, 201103 (2013).

[5] Y. Wu, X. Yan, X. Zhang, X. Ren. Appl. Phys. Lett., 109, 183101 (2016).

[6] J.M. Lee, J.W. Choung, J. Yi, D.H. Lee, M. Samal, D.K. Yi, C.-H. Lee, G.-C. Yi, U. Paik, J.A. Rogers, W.I. Park. Nano Lett., 10, 2783 (2010).

[7] K.V. Emtsev, A. Bostwick, K. Horn, J. Jobst, G.L. Kellogg, L. Ley, J.L. McChesney, T. Ohta, S.A. Reshanov, J. Röhrl, E. Rotenberg. Nature Materials, 8, 203 (2009).

[8] V.Y. Davydov, D.Y. Usachov, S. Lebedev, A. Smirnov, V. Levitskii, I. Eliseyev, P. Alekseev, M. Dunaevskiy, O.Y. Vilkov, A. Rybkin, A.A. Lebedev. Semiconductors, 51, 1072 (2017).

[9] A.M. Munshi, D.L. Dheeraj, V.T. Fauske, D.-C. Kim, A.T. van Helvoort, B.-O. Fimland, H. Weman. Nano Lett., 12, 4570 (2012).

[10] J.-H. Kang, Y. Ronen, Y. Cohen, D. Convertino, A. Rossi, C. Coletti, S. Heun, L. Sorba, P. Kacman, H. Shtrikman. Semicond. Sci. Technol., 31, 115005 (2016).

[11] M. Heilmann, A.M. Munshi, G. Sarau, M. Göbelt, C. Tessarek, V.T. Fauske, A.T. van Helvoort, J. Yang, M. Latzel, B. Hoffmann, G. Coniberr. Nano Lett., 16, 3524 (2016).

[12] V. Panchal, R. Pearce, R. Yakimova, A. Tzalenchuk, O. Kazakova. Sci. Rep., 3, 2597 (2013).

[13] V. Trukhin, A. Buyskikh, N. Kaliteevskaya, A. Bourauleuv, L. Samoilov, Y.B. Samsonenko, G. Cirlin, M. Kaliteevski, A. Gallant. Appl. Phys. Lett., 103, 072108 (2013).

[14] G. Cirlin, I. Shtrom, R. Reznik, Y.B. Samsonenko, A. Khrebtov, A. Bouravleuv, I. Soshnikov. Semiconductors, 50, 1421 (2016).

[15] V. Kumaresan, L. Largeau, A. Madouri, F. Glas, H. Zhang, F. Oehler, A. Cavanna, A. Babichev, L. Travers, N. Gogneau, M. Tchernycheva. Nano Lett., 16, 4895 (2016).

[16] S. Fernández-Garrido, M. Ramsteiner, G. Gao, L.A. Galves, B. Sharma, P. Corfdir, G. Calabrese, Z. de Souza Schiaber, C. Pfüller, A. Trampert, J.M.J. Lopes. Nano Lett., 17, 5213 (2017).

[17] P. Alekseev, P. Geydt, M. Dunaevskiy, E. Lähderanta, T. Haggrén, J.-P. Kakko, H. Lipsanen. Appl. Phys. Lett., 111, 132104 (2017).

[18] S.M. Sze, K.K. Ng. Physics of Semiconductor Devices (John Wiley \& Sons, 2006).

[19] P.A. Alekseev, M.S. Dunaevskiy, V.P. Ulin, T.V. Lvova, D.O. Filatov, A.V. Nezhdanov, A.I. Mashin, V.L. Berkovits. Nano Lett., 15, 63 (2015).

[20] P.A. Alekseev, M.S. Dunaevskiy, G.E. Cirlin, R.R. Reznik, A.N. Smirnov, D.A. Kirilenko, V.Yu. Davydov, V.L. Berkovits. Nanotechnology, 29, 314003 (2018).

Редактор Г.А. Оганесян

\section{Electrical properties of GaAs nanowires grown on the graphene/SiC hybrid substrates}

\author{
P.A. Alekseev1 ${ }^{1}$ M.S. Dunaevskiy ${ }^{1}$, A.O. Mikhailov', \\ S.P. Lebedev ${ }^{2}$, A.A. Lebedev ${ }^{1}$, I.V. Ilkiv ${ }^{3}$, \\ A.I. Khrebtov ${ }^{2}$, A.D. Bouravleuv 1,3,4, G.E. Cirlin $2,3,4$ \\ ${ }^{1}$ loffe Institute, \\ 194021 St. Petersburg, Russia \\ 2 ITMO University, \\ 197101 St. Petersburg, Russia \\ 3 St. Petersburg Academic University, \\ 194021 St. Petersburg, Russia \\ ${ }^{4}$ Institute for Analytical Instrumentation, \\ Russian Academy of Sciences, \\ 190103 St. Petersburg, Russia
}

Abstract Electrical properties of GaAs nanowires grown on (0001) $6 \mathrm{H}$-SiC substrate covered by mono- and bilayer graphene were studied. Nanowires were grown by molecular beam epitaxy using gold as a catalyst. The electrical properties were studied by measuring and analyzing the current-voltage characteristics of single nanowires vertically growing on a substrate. Numerical simulation of the measured $I-V$ curves revealed the presence of a Schottky barrier of $\sim 0.6 \mathrm{~V}$ height between nanowires and graphene. The occurrence of the barrier is associated with the formation of excess arsenic at the interface of nanowire/graphene. 